\title{
GENOMIC ANALYSIS OF PLANT-ASSOCIATED BACTERIA AND THEIR POTENTIAL IN ENHANCING PHYTOREMEDIATION EFFICIENCY
}

\author{
Artur Piński' ${ }^{1}$, Katarzyna Hupert-Kocurek ${ }^{1}$ \\ 1 The University of Silesia in Katowice, Faculty of Biology and Environmental Protection, Jagiellonska 28, \\ 40-032 Katowice, Poland, e-mail: arturpinski@gmail.com
}

Received: 2017.04.24

Accepted: 2017.05.31

Published: 2017.07.01

\begin{abstract}
Phytoremediation is an emerging technology that uses plants in order to cleanup pollutants including xenobiotics and heavy metals from soil, water and air. Inoculation of plants with plant growth promoting endophytic and rhizospheric bacteria can enhance efficiency of phytoremediation. Genomic analysis of four plant-associated strains belonging to the Stenotrophomonas maltophilia species revealed the presence of genes encoding proteins involved in plant growth promotion, biocontrol of phytopathogens, biodegradation of xenobiotics, heavy metals resistance and plant-bacteria-environment interaction. The results of this analysis suggest great potential of bacteria belonging to Stenotrophomonas maltophilia species in enhancing phytoremediation efficiency.
\end{abstract}

Keywords: endophytic bacteria, rhizospheric bacteria, Stenotrophomonas maltophil$i a$, heavy metals, phytoremediation, xenobiotics

\section{INTRODUCTION}

Phytoremediation is gaining importance as technology that uses plants for cleanup of soil, water and air contaminated with a number of pollutants including xenobiotics and heavy metals. It is regarded as the efficient and cost effective ecofriendly technology. Inoculation of plants with scrupulously selected plant-associated bacteria has been proven to enhance efficiency of phytoremediation processes. Endophytic and rhizospheric bacteria are able to promote growth of plants used in phytoremediation through various ways which result in alleviation of toxicity of contaminants and enhancement of plant biomass production [Ma et al. 2016; Mcguinness and Dowling 2009] Selection of proper plant-associated bacteria for the enhancement of phytoremediation requires extensive testing and thoroughly understanding of plant-bacteria-environment interactions. Analysis of fully sequenced genomes of bacterial strains can provide additional data about such interaction as well as information about their resistance to heavy metals and xenobiotics degradation abilities [Ali et al. 2014].
Stenotrophomonas maltophilia is an aerobic, catalase-positive, oxidase-positive, Gram-negative rod belonging to Gammaproteobacteria, commonly found in variety of habitats including food, water and soil. It is often associated with plants residing in rhizosphere and in internal tissues of its host [Huang et al. 2009; Mukherjee and Roy 2016]. S. maltophilia is also an emerging global opportunistic nosocomial pathogen. Treatment of S. maltophilia infection is challenging because of its intrinsic resistance to broad array of antibiotics [Alavi et al. 2014; Mukherjee and Roy 2016]. Multi-drug resistance favors survival and growth in highly competitive soil and plant related environment. S. maltophilia strains are also able to promote growth of its plant host and to inhibit growth of phytopathogens through the production of chitinases, proteases, lysozyme, and secondary metabolites such as pyrrolnitrin, enterobactin and phenazine [Wu et al. 2015; Zhang and Yuen 1999]. It has been reported that S. maltophilia strains are capable of degrading xenobiotics such as monocyclic aromatic hydrocarbons [Guzik et al. 2013], drugs [Guzik et al. 2009], and pesticides [Wang et al. 2015]. Additionally, in many of 
S. maltophilia strains resistance to heavy metals was also observed [Ghosh and Das 2013]

To effectively promote growth of its plant host, bacterium must possess certain traits that make it possible to penetrate plant avoiding response from the immune system and to establish colony in the internal tissues of plant. Bacteria capable of residing in the inner tissues of plants without causing any apparent disease are recognized as endophytes [Reinhold-Hurek and Hurek 2011].

The aim of this work was to evaluate the genetic potential of four plant-associated strains RR-10, R551-3, B418 and SeITE02 that belong to Stenotrophomonas maltophilia species in aspect of their usefulness in enhancing the phytoremediation (Table 1, Figure 1). Genes encoding proteins involved in plant growth promotion, biocontrol of phytopathogens, biodegradation of xenobiotics, heavy metal resistance and bacteriaplant interaction were considered.

\section{MATERIALS AND METHODS}

The genomic sequence of RR-10, R551-3, B418 and SeITE02 strains were downloaded from PATRIC database [Wattam et al. 2014]. The phylogenetic tree of the 10 Stenotrophomonas maltophilia genomes was constructed based on the concatenation of 21 housekeeping genes determined by AMPHORA2 algorithm with Neighbor Joining method and rooted by Stenotrophomonas rhizophila DSM14405 using Geneious v. 10.0.9 [Kearse et al. 2012; Kerepesi, Bánky, and Grolmusz 2014]. Secondary metabolites clusters were identified with antiSMASH v. 3.0 [Weber et al. 2015]. Genes encoding proteins involved in plant growth promotion, biocontrol of phytopathogens, biodegradation of xenobiotics and heavy metals resistance were identified with Comparative Pathway Tool implemented in PAT-
RIC database and through direct blasting [Wattam et al. 2014]. Subcellular localization of proteins was predicted by PSORTb v3.0 program [Yu et al. 2010]. Classification of proteins into families and prediction of domains were performed using InterPro 61.0 [Finn et al. 2017]. Analysis and annotation of carbohydrate active enzymes were performed by CAZymes Analysis Toolkit [Byung and Karpinets 2010].

\section{RESULTS AND DISCUSSION}

\section{Promotion of plant growth}

Phosphorus is an essential macronutrient important for the development of plants and its deficiency results in halted growth and in darkening of leaves. However, a large portion of applied phosphorus fertilizers in form of soluble inorganic phosphorus is quickly immobilized and becomes unavailable to plants. Solubilization of poorly or insoluble mineral phosphates can be achieved by production of acid phosphatases. Genes encoding secreted bacterial nonspecific acid phosphatases were identified in the genomes of all analyzed strains (Figure 2) [Gandhi and Chandra 2012].

From seventeen genes organized in phn operon present in the genome of Escherichia coli known to be involved in phosphonate degradation and uptake [Xie et al. 2016], only phnA gene encoding phosphonoacetaldehyde hydrolase was found to be present in the genomes of strains RR10, R551-3, B418 and SeITE02. About 10-50\% of total phosphorus in soil can occur in form of organic phosphorus, particularly phytates which are hydrolyzed by phytases (phyA) to less-phosphorylated myo-inositol derivatives and inorganic phosphate [Singh, Kumar, and Agrawal 2014]. Performed comparative genomics reviled the presence of genes encoding phytases and pst op-

Table 1. The general characteristic of genomes of analyzed strains belonging to the S. maltophilia species; WGS - Whole Genome Sequencing.

\begin{tabular}{|l|c|c|c|c|}
\hline \multicolumn{1}{|c|}{ Bacterial strain } & RR-10 & R551-3 & B418 & SelTE02 \\
\hline Host name & Oryza sativa & $\begin{array}{c}\text { Populus trichocarpa x P. } \\
\text { deltoides }\end{array}$ & Hordeum vulgare & $\begin{array}{c}\text { Astragalus } \\
\text { bisculcatus }\end{array}$ \\
\hline Isolation source & root & root/shoot & rhizosphere & rhizosphere \\
\hline Genome status & WGS & Complete & WGS & WGS \\
\hline Number of bases & $4,657,427$ & $4,573,969$ & $4,688,249$ & $4,557,110$ \\
\hline GC content [\%] & 66.3 & 66.3 & 65.5 & 66.4 \\
\hline Number of CDSs & 4160 & 4097 & 4071 & 4081 \\
\hline Average ORF length & 965 & 980 & 981 & 978 \\
\hline
\end{tabular}




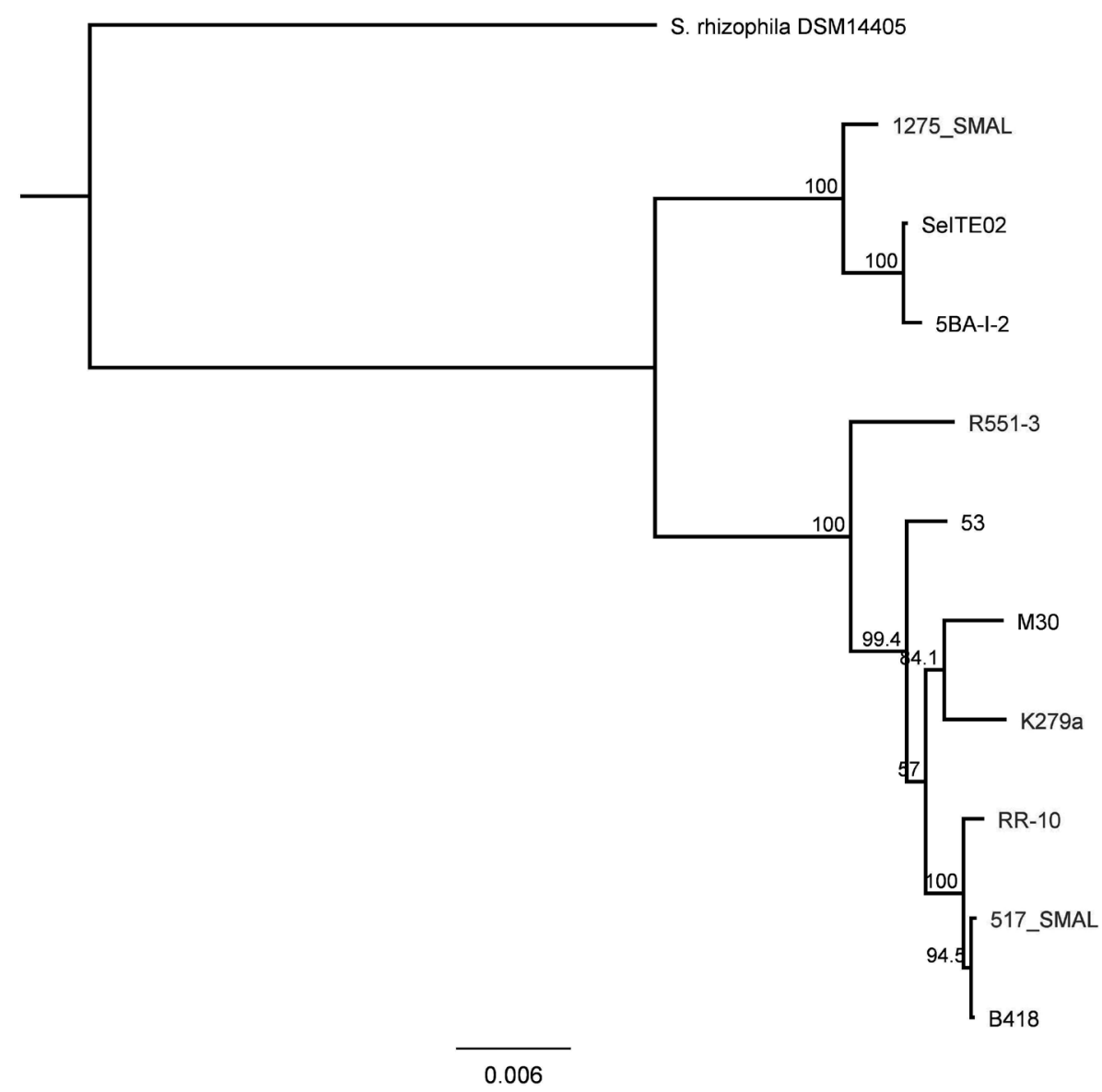

Figure 1. The phylogenetic tree of endophytic and rhizospheric bacteria based on 21 concatenated protein sequences of housekeeping genes determined by AMPHORA algorithm rooted with outgroup strain Stenotrophomonas rhizophila DSM14405.

eron ( $p s t A B C S)$ engaged in phosphate transport in the studied genomes [Xie et al. 2016]. Regulation of phosphonate uptake is controlled by two component system consisting of two protein encoded by $p h o P$ and $p h o R$ genes which were also localized in the genomes of analyzed $S$. maltophilia strains (Figure 2). Obtained results suggest that analyzed strains are phosphate solubilizing bacteria (PSB) with the ability to effectively supply phosphate to its plant host.

Polyamines are small aliphatic polycations which play an important role in cell division and differentiation, replication, transcription, translation, protein synthesis and membrane stability. The most commonly occurring polyamine, putrescine can be synthetize through canonical biosynthesis pathway by ornithine decarboxylase or alternatively in two step pathway catalyzed by arginine decarboxylase (speA), agmatinase $(s p e B)$ and spermidine synthase (speE). Specific transport of putrescine is possible thanks to putrescine transport system encoded by the genes of
potFGHI operon [Miller-Fleming and Olin-Sandoval 2015]. In the genomes of RR-10, R551-3, B418 and SeITE02, genes encoding enzymes of the alternative way of putrescine biosynthesis and putrescine transport were identified (Figure 2) suggesting their ability to produce and secrete putrescine. Additionally, all strains possess cadA gene encoding lysine decarboxylase engage in cadaverine synthesis (Figure 2). Spermidine is exported by spermidine excretion protein complex formed by two proteins, MdtI and MdtJ, which also participate in multidrug resistance [Higashi et al. 2008]. Comparative genomic reveals the presence of genes encoding spermidine transport $(m d t J I)$ in the genomes of all strains: RR-10, R551-3, B418 and SeITE02 (Figure 2).

\section{Biocontrol of phytopathogens}

Protective role of chitinases against phytopathogens results from the degradation of fungus cell wall, which results in inhibition of fungal 


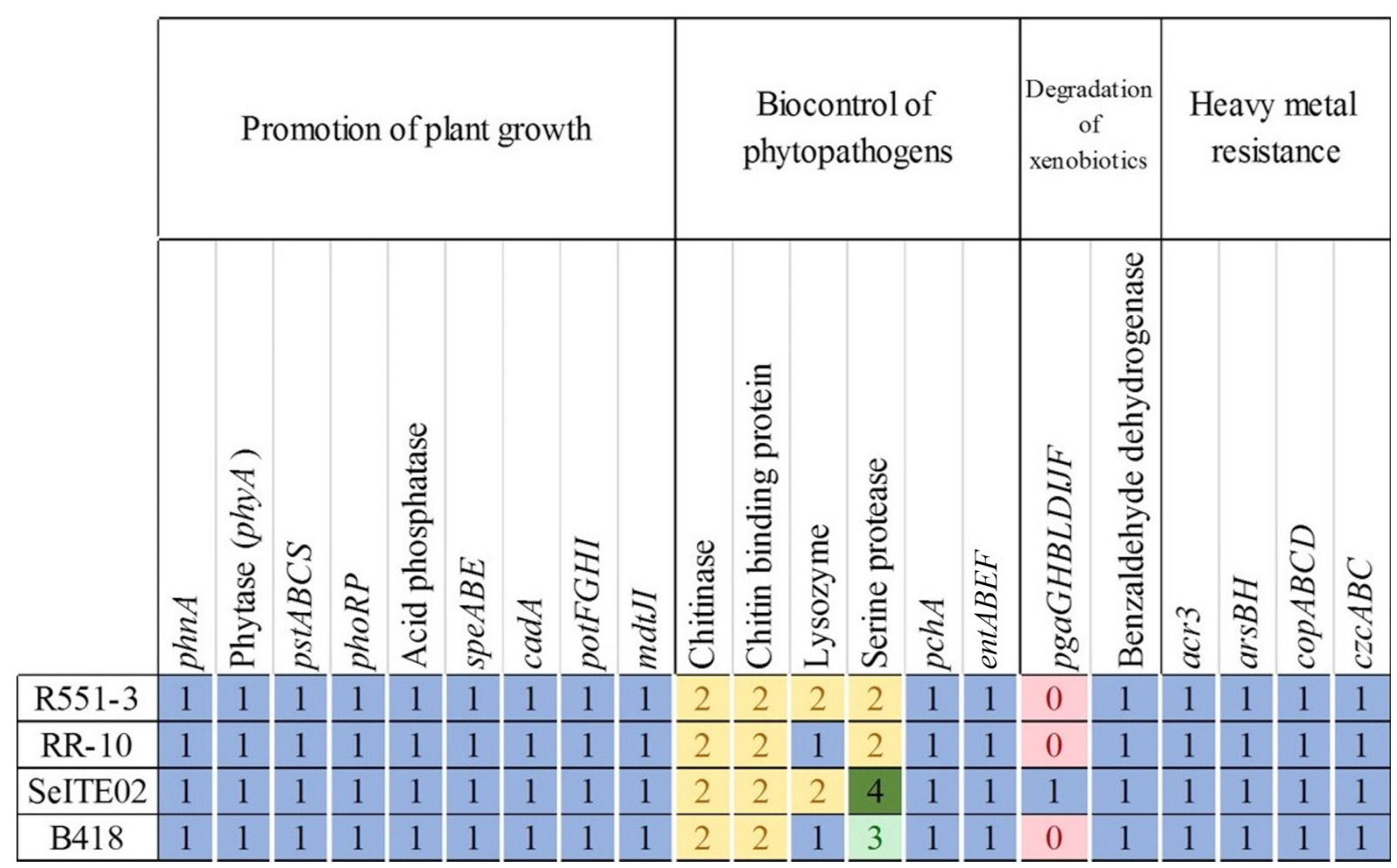

Figure 2. The presence of genes encoding proteins involved in plant growth promotion, biocontrol of phytopathogens, biodegradation of xenobiotics, heavy metals resistance in the genomes of analyzed S. maltophilia RR-10, R551-3, B418 and SeITE02 strains.

growth and in release of oligo-N-acetylglucosamines eliciting plant defense response [Wang et al. 2014]. Performed analysis showed that all of four analyzed strains possess two genes encoding chitinases (Figure 2). Both of these enzymes belong to the family 18 of the glycosyl hydrolases. Chitinase of the higher molecular mass beside catalytic domain comprises of chitin binding domain, polycystic kidney disease domain (PKD) and fibronectin type III domain. Some chitin degrading organisms produce additional proteins capable of binding to carbohydrates and facilitating their degradation [Purushotham et al. 2012]. In all of the analyzed strains two genes encoding such proteins were found and based on CAZy database classification both of them were classified to the auxiliary activity family 10 - AA10 (formerly CBM33) (Figure 2). Lysozyme catalyzes hydrolysis of 1.4-D-linkage between $\mathrm{N}$-acetylmuramic acid and $\mathrm{N}$-acetylglucosamine of bacterial cell wall leading to the cell death by lysis. Lysozyme as a self-defence enzyme is produced by plants, animals and plant-associated bacteria which may through excretion of lysozyme inhibit growth of bacterial pathogens [Wang et al. 2005]. Two putative genes encoding lysozyme were found in the genomes of SeITE02 and R551-3 while one pu- tative gene was located in the genomes of B418 and RR-10 (Figure 2). Extracellular protease can also contribute to the inhibition of the growth of plant pathogens like fungus and root-knot nematode [Kupferschmied, Maurhofer, and Keel 2013]. Putative genes encoding serine proteases were also present in all of the researched genomes (Figure 2). Strain SeITE02 possess four genes for this enzyme while in strain B418 and in strains R551-3 and RR-10 only three and two serine proteases genes were detected respectively (Figure 2). Chitinases, lysozyme and proteases can act synergistically in biocontrol of phytopathogens. Conducted analysis prove that all four strains are genetically equipped to biocontrol both bacterial and fungal pathogens.

Iron is an indispensable element required by microorganisms and plants for proper development. Despite great abundance of iron in soil most of it exists in the form of $\mathrm{Fe}^{3+}$ which is not bioavailable. To cope with the iron deficiency bacteria utilize siderophores which solubilize and bind $\mathrm{Fe}^{3+}$ forming siderophore- $\mathrm{Fe}^{3+}$ complexes that can be taken up by active transport mechanisms. Siderophores produced by endophytic and rhizospheric bacteria may limit bioavailability of iron to the phytopathogens thus constraining their 
growth [Liaqat and Eltem 2016]. In the genomes of all four plant-associated strains genes responsible for biosynthesis of enterobactin (entABEF), a catechol-type siderophore, were found (Figure 2) [García et al. 2015; Kanehisa et al. 2017]. Genes located in the genomes of analyzed strains indicated ability to synthesize siderophores therefore provide bioavailable iron to plant host and constrain growth of phytopathogens.

\section{Degradation of xenobiotics}

Degradation of xenobiotics by endophytic and rhizospheric bacteria can contribute to the cleanup of contaminated soil and could have potential for improving phytoremediation [Mcguinness and Dowling 2009]. Analyzed strains do not possess extensive degradation abilities except SeITE02 which possess genes encoding enzymes engaged in protocatechuic acid degradation through the ortho-cleavage of the aromatic ring (Figure 2). The first step is catalyzed by two-subunit protocatechuate 3.4-dioxygenase ( $\mathrm{pgaGH}$ ) yielding 3-carboxy-cis, cis-muconate. Subsequent steps of degradation of 3-carboxy-cis,cis-muconate to the citric acid cycle intermediates are catalyzed by product of pgaBLDIJF genes [Iwagami, Yang, and Davies 2000]. In the genomes of all four strains genes encoding benzaldehyde dehydrogenase were found yet no genes that would encode for enzymes of further degradation of benzoate or its derivatives were present (Figure 2). Result of the performed analyses show that only strain SeITE02 possess all necessary genes encoding enzymes engaged in protocatechuic acid degradation suggesting that only this strain can be useful in phytodegradation.

\section{Heavy metal resistance}

The presence of bioavailable heavy metals in soil can adversely influence growth of plantassociated bacteria hence lowering efficiency of plant growth promotion and in result bacterial assisted phytoremediation [Ma et al. 2016]. Several genes encoding proteins conferring resistance to heavy metals were found in the genomes of RR-10, R551-3, B418 and SeITE02 (Figure 2). Arsenical-resistance protein ACR3 encoded by acr3 gene is an efflux protein that confers resistance to arsenic by extrusion from cells. Other genes linked to the arsenic resistance namely ars $B$ and ars $H$ encoding arsenic efflux pump protein and arsenic resistance protein ArsH respectively [Wang et al. 2009]. Copper resistance in analyzed strains seems to be attributed to the presence of proteins which are products of expression of copABCD gene cluster [Bondarczuk and Piotrowska-Seget 2013]. The three-component Czc chemiosmotic efflux pump consisting of inner membrane $(c z c A)$, outer membrane $(c z c C)$, and membrane-spanning $(c z c B)$ proteins conferring resistance to cobalt, zinc and cadmium [Silver and Phung 1996]. The presence of the above genes indicated that RR-10, R551-3, B418 and SeITE02 strains are able to survive in heavy metals contaminated environment and possibly improve phytoextraction efficiency.

\section{Bacteria-plant interaction and colonization}

Root exudates attract bacteria which gather in the area surrounding roots. Bacterial motion can be result of following water fluxes or can be achieved by the use of flagella or by retraction of type IV pili [Taghavi and van der Lelie 2010]. Genes encoding structural proteins of flagella and proteins responsible for chemotactic movement of bacteria toward rhizoplane as well as genes encoding type IV pili (pilA, pilT and pilU) needed for twitching motility were found to be present in genomes of all four S. maltophilia strains (Figure 3).

Next step in colonization of plants by bacteria is adhesion which may be possible due to the hemagglutinin, adhesin, type IV pili, cellulose biosynthesis and biofilm formation [Compant, Clément, and Sessitsch 2010]. In the genomes of RR-10, R551-3, B418 and SeITE02 biosynthesis genes for hemagglutinin, adhesins, type IV pili were also identified (Figure 3). Biosynthesis cluster for cellulose comprised of four genes gathered in operon $b c s A B C D$ was found only in the genome of SeITE02 (Figure 3). Biofilm formation by RR-10, R551-3, B418 and SeITE02 is possible due to the presence of gene products of the pgaABCD operon (Figure 3) which catalyze formation and export of linear homopolymer poly- $\beta-1.6-\mathrm{N}$-acetyl-Dglucosamine which serves as a scaffold of biofilm [Itoh et al. 2008]. SmeDEF efflux pump present in all of so far studied S. maltophilia strains play an important role in colonization. Expression of genes encoding SmeDEF pump is upregulated by plant-produced flavonoids and deletion of $s m e E$ impairs colonization of plants [García-León et al. 2014]. Bacteria during penetration of plant root 
epidermis can rely on natural discontinuities of rhizodermis or enzymatic activity of CWDE (cell wall degrading enzymes) such as cellulase and xylanase [Pedrosa et al. 2011]. Strain SeITE02 possess both xylanase and extracellular endoglucanase while strains RR-10 and R551-3 carry only one copy of gene encoding xylanase (Figure $3)$. The presence of CWDE suggests that those S. maltophilia strains are an active colonizer of plant-associated environment.

The reactive-oxygen rich environment of the inside of plant is challenging for bacterial cells thus endophytes must be equipped with various mechanisms to survive. In the genomes of RR10, R551-3, B418 and SeITE02 genes encoding catalases, superoxide dismutases and thiol peroxidases were found (Figure 3). Expression of those genes is regulated by hydrogen-peroxide sensor OxyR which activates the expression of a regulon of hydrogen peroxide-inducible genes. Also, genes required for biosynthesis of glutathione and trehalose (ots $A B)$ were identified [Compant, Clément, and Sessitsch 2010; Taghavi and van der Lelie 2010]. During colonization, bacterial endophytes can communicate with plant cells trough production and secretion of effector proteins in order to avoid response from plant immune system [Ali et al. 2014]. Secretion of effector proteins can occur through the type I, II and IV secretion system which structural proteins are encoded by genes present in the genomes of all analyzed strains (Figure 3). The quorum-sensing (QS) system present in S. maltophilia is based on the signaling molecule diffusible signal factor (DSF) which positively influences plants colonization and promotion of plant growth [Alavi et al. 2013]. Production and detection of DSF is directed by $r p f$ cluster which was divided based on variation of N-terminal region of $r p f F$ protein to two populations: $r p f F-1$ and $r p f F-2$. Only strains that belong to the $r p f F-1$ population display detectable DSF production [Huedo et al. 2014]. Base on sequence similarity analysis, $r p f F$ gene of R551-3, RR-10 and B418 belong to the rpfF-1 population and SeITE02 to the $r p f F-2$ suggesting inability to produce DSF (Figure 3). Result of analysis indicated that R551-3, RR-10 and B418 are capable of production and detection of DSF which may positively influences plants colonization.

\begin{tabular}{|c|c|c|c|c|c|c|c|c|c|c|c|}
\hline & \multicolumn{11}{|c|}{ Bacteria-plant interaction and colonization } \\
\hline & $\underset{\mathbb{2}}{\mathbb{Z}}$ & 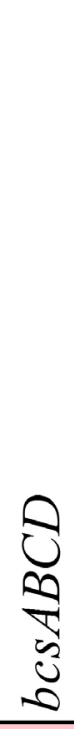 & $\begin{array}{l}0 \\
0 \\
0 \\
0 \\
0 \\
0 \\
2\end{array}$ & 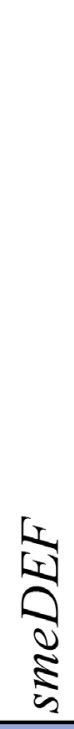 & 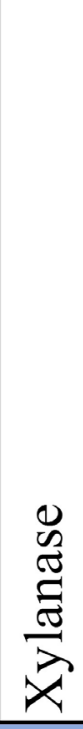 & 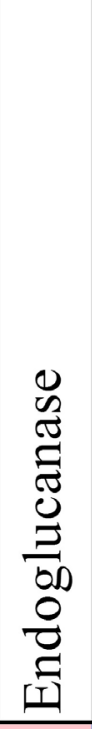 & $\frac{\infty}{3}$ & 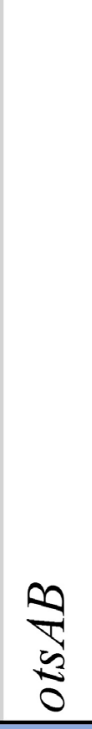 & 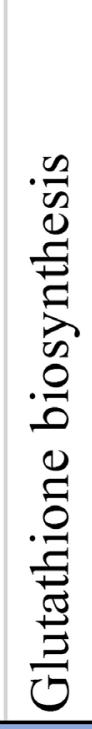 & 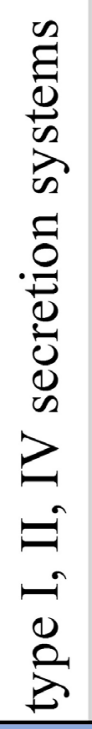 & $\begin{array}{l}\mathbf{L} \\
\hat{\theta}\end{array}$ \\
\hline R551-3 & 1 & 0 & 1 & 1 & 1 & 0 & 1 & 1 & 1 & 1 & 1 \\
\hline RR-10 & 1 & 0 & 1 & 1 & 1 & 0 & 1 & 1 & 1 & 1 & 1 \\
\hline SeITE02 & 1 & 1 & 1 & 1 & 1 & 1 & 1 & 1 & 1 & 1 & 1 \\
\hline B418 & 1 & 0 & 1 & 1 & 1 & 0 & 1 & 1 & 1 & 1 & 1 \\
\hline
\end{tabular}

Figure 3. The presence of genes encoding proteins involved in bacteria-plant interaction and colonization in the genomes of analyzed S. maltophilia RR-10, R551-3, B418 and SeITE02 strains. 


\section{CONCLUSION}

Comparative analysis of the genomes of four plant-associated bacteria belonging to Stenotrophomonas maltophilia species revealed their potential in enhancement of phytoremediation efficiency. Analysis of the genomes of R551-3, RR10 B418 and SeITE02 strains enabled identification of genes encoding proteins involved in plant growth promotion, biocontrol of phytopathogens, biodegradation of xenobiotics, heavy metals resistance and plant-bacteria-environment interactions. Based on the presence of analyzed genes, strain SeITE02 presents itself as the strain with the greatest potential in enhancement of phytoremediation efficiency. Strain SeITE02 compare to the remaining strains possess additional genes encoding serine proteases and enzymes engaged in protocatechuic acid degradation through the ortho-cleavage of the aromatic ring. This strain is also in possession of unique genes enabling biosynthesis of cellulose and endoglucanase which are involved in bacteria-plant interaction suggesting that SeITE02 strain is an efficient colonizer of plant-associated environment.

\section{REFERENCES}

1. Alavi, P., Muller, H., Cardinale, M., Zachow, C., Sanches, M., Martinez, L., Berg, G. 2013. The DSF quorum sensing system controls the positive influence of Stenotrophomonas maltophilia on plants. PLoS ONE, 8(7), 1-9.

2. Alavi, P., Starcher, M. R., Thallinger, G. G., Zachow, C., Müller, H., Berg, G. 2014. Stenotrophomonas comparative genomics reveals genes and functions that differentiate beneficial and pathogenic bacteria. BMC Genomics, 15, 482.

3. Ali, S., Duan, J., Charles, T. C., Glick, B. R. 2014. A bioinformatics approach to the determination of genes involved in endophytic behavior in Burkholderia spp. Journal of Theoretical Biology, 343, 193-198.

4. Bondarczuk, K., Piotrowska-Seget, Z. 2013. Molecular basis of active copper resistance mechanisms in Gram-negative bacteria. Cell Biology and Toxicology, 29, 397-405.

5. Byung, P., Karpinets, T. V. 2010. CAZymes Analysis Toolkit (CAT): Web service for searching and analyzing carbohydrate-active enzymes in a newly sequenced organism using CAZy database. Glycobiology, 20(12), 1574-1584.

6. Compant, S., Clément, C., Sessitsch, A. 2010. Plant growth-promoting bacteria in the rhizo- and endosphere of plants: Their role, colonization, mechanisms involved and prospects for utilization.
Soil Biology Biochemistry, 42, 669-678.

7. Finn, R. D., Attwood, T. K., Babbitt, P. C., Bateman, A., Bork, P., Bridge, J., ... Mitchell, A. L. 2017. InterPro in 2017 - beyond protein family and domain annotations. Nucleic Acids Research, 45, 190-199.

8. Gandhi, N. U., Chandra, S. B. (2012). A comparative analysis of three classes of bacterial non-specific acid phosphatases and archaeal phosphoesterases: evolutionary perspective. Acta Inform Med, 20(3), 167-173.

9. García-León, G., Hernández, A., Hernando-Amado, S., Alavi, P., Berg, G., Martínez, L. 2014. A function of SmeDEF, the major quinolone resistance determinant of Stenotrophomonas maltophil$i a$, is the colonization of plant roots. Applied and Environmental Microbiology, 80(15), 4559-4565.

10. García, C. A., Alcaraz, E. S., Franco, M. A., Rossi, B. N. P. De. 2015. Iron is a signal for Stenotrophomonas maltophilia biofilm formation, oxidative stress response, OMPs expression, and virulence. Frontiers in Microbiology, 6, 1-14.

11. Ghosh, A., Das, P. 2013. Optimization of copper bioremediation by Stenotrophomonas maltophilia PD2. Journal of Environmental Chemical Engineering, 1(3), 159-163.

12. Guzik, U., Greń, I., Wojcieszyńska, D., Sylwia, Ł. 2009. Isolation and characterization of a novel strain of Stenotrophomonas maltophilia possessing various dioxygenases for monocyclic hydrocarbon degradation. Brazilian Journal of Microbiology, 40, 285-291.

13. Guzik, U., Hupert-Kocurek, K., Sitnik, M., Wojcieszyńska, D. 2013. High activity catechol 1.2-dioxygenase from Stenotrophomonas maltophilia strain $\mathrm{KB} 2$ as a useful tool in cis,cis-muconic acid production. Antonie van Leeuwenhoek, 103, 1297-1307.

14. Higashi, K., Ishigure, H., Demizu, R., Uemura, T., Nishino, K., Yamaguchi, A., ... Igarashi, K. 2008. Identification of a spermidine excretion protein complex (MdtJI) in Escherichia coli. Journal of Bacteriology, 190(3), 872-878.

15. Huang, X., Liu, J., Ding, J., He, Q., Xiong, R. 2009. The investigation of nematocidal activity in Stenotrophomonas maltophilia G2 and characterization of a novel virulence serine protease. Canadian Journal of Microbiology, 942, 934-942.

16. Huedo, P., Yero, D., Martínez-servat, S., Estibariz, I., Planell, R., Martínez, P., Ruyra, À. (2014). Two different $r p f$ clusters distributed among a population of Stenotrophomonas maltophilia clinical strains display differential diffusible signal factor production and virulence regulation. Journal of Bacteriology, 196(13), 2431-2442.

17. Itoh, Y., Rice, J. D., Goller, C., Pannuri, A., Taylor, J., Meisner, J., ... Romeo, T. 2008. Roles of pgaABCD genes in synthesis, modification, and export of the Escherichia coli biofilm adhesin 
poly-beta-1.6-n-acetyl-d-glucosamine. Journal of Bacteriology, 190(10), 3670-3680.

18. Iwagami, S., Yang, K., Davies, J. (2000). Characterization of the protocatechuic acid catabolic gene cluster from Streptomyces sp. strain 2065. Applied and Environmental Microbiology, 66(4), 1499-1508.

19. Kanehisa, M., Furumichi, M., Tanabe, M., Sato, Y., Morishima, K. 2017. KEGG: new perspectives on genomes, pathways, diseases and drugs. Nucleic Acids Research, 45, 353-361.

20. Kearse, M., Moir, R., Wilson, A., Stones-Havas, S., Sturrock, S., Buxton, S., ... Drummond, A. 2012. Geneious Basic: An integrated and extendable desktop software platform for the organization and analysis of sequence data. Bioinformatics, 28(12), 1647-1649.

21. Kerepesi, C., Bánky, D., Grolmusz, V. 2014. AmphoraNet: The webserver implementation of the AMPHORA2 metagenomic work flow suite. Gene, 533(2), 538-540.

22. Kupferschmied, P., Maurhofer, M., Keel, C. 2013. Promise for plant pest control: root-associated pseudomonads with insecticidal activities. Frontiers in Plant Science, 4, 287.

23. Liaqat, F., Eltem, R. (2016). Identification and characterization of endophytic bacteria isolated from in vitro cultures of peach and pear rootstocks. 3 Biotech, 6(2), 1-8.

24. Ma, Y., Rajkumar, M., Zhang, C., Freitas, H. 2016. Beneficial role of bacterial endophytes in heavy metal phytoremediation. Journal of Environmental Management, 174, 14-25.

25. Mcguinness, M., Dowling, D. 2009. Plant-associated bacterial degradation of toxic organic compounds in soil. International Journal of Environmental Research and Public Health, 6, 2226-2247.

26. Miller-Fleming, L., Olin-Sandoval, V. 2015. Remaining mysteries of molecular biology: the role of polyamines in the cell. Journal of Molecular Biology, 427(21), 3389-3406.

27. Mukherjee, P., Roy, P. 2016. Genomic potential of Stenotrophomonas maltophilia in bioremediation with an assessment of its multifaceted role in our environment. Frontiers in Microbiology, 7, 1-14.

28. Pedrosa, F. O., Monteiro, R. A., Wassem, R., Cruz, L. M., Ayub, R. A., Colauto, N. B., ... Souza, E. M. 2011. Genome of Herbaspirillum seropedicae strain SmR1, a specialized diazotrophic endophyte of tropical grasses. PLoS Genetics, 7(5).

29. Purushotham, P., Arun, P. V. P. S., Prakash, J. S. S., Podile, A. R. 2012. Chitin binding proteins act synergistically with chitinases in Serratia proteamaculans 568. PLoS ONE, 7(5), 1-10.

30. Reinhold-Hurek, B., Hurek, T. 2011. Living inside plants: Bacterial endophytes. Current Opinion in Plant Biology, 14, 435-443.

31. Silver, S., Phung, L. T. 1996. Bacterial heavy metal resistance: new surprises. Annual Review of Microbiology, 50, 753-789.

32. Singh, P., Kumar, V., Agrawal, S. 2014. Evaluation of phytase producing bacteria for their plant growth promoting activities. International Journal of Microbiology.

33. Taghavi, S., van der Lelie, D. 2010. Genome sequence of the plant growth-promoting endophytic bacterium Enterobacter sp. 638. Molecular Microbial Ecology of the Rhizosphere, 2(5), 899-908.

34. Wang, L., Jeon, B., Sahin, O., Zhang, Q. 2009. Identification of an arsenic resistance and arsenic-sensing system in Campylobacter jejuni. Applied and Environmental Microbiology, 75(15), 5064-5073.

35. Wang, M., Xing, Y., Wang, J., Xu, Y., Wang, G. 2014. The role of the chil gene from the endophytic bacteria Serratia proteamaculans 336x in the biological control of wheat take-all. Canadian Journal of Microbiology, 60(8), 533-40.

36. Wang, S., Ng, T. B., Chen, T., Lin, D., Wu, J., Rao, P., Ye, X. (2005). First report of a novel plant lysozyme with both antifungal and antibacterial activities. Biochemical and Biophysical Research Communications, 327(3), 820-827.

37. Wang, Y., Zheng, X., Hu, Q., Zheng, Y. 2015. Degradation of abamectin by newly isolated Stenotrophomonas maltophilia ZJB-14120 and characterization of its abamectin-tolerance mechanism. Research in Microbiologoy, 166(5), 1-11.

38. Wattam, A. R., Abraham, D., Dalay, O., Disz, T. L., Driscoll, T., Gabbard, J. L., ... Sobral, B. W. 2014. PATRIC, the bacterial bioinformatics database and analysis resource. Nucleic Acids Research, 42, 581-591.

39. Weber, T., Blin, K., Duddela, S., Krug, D., Kim, H. U., Bruccoleri, R., ... Medema, M. H. 2015. antiSMASH 3.0 - a comprehensive resource for the genome mining of biosynthetic gene clusters. Nucleic Acids Research, 43, 237-243.

40. Wu, Y., Wang, Y., Li, J., Hu, J., Chen, K., Wei, Y., ... Yang, H. 2015. Draft genome sequence of Stenotrophomonas maltophilia strain B418, a promising agent for biocontrol of plant pathogens and root-knot nematode. Genome Announcements, 3(1), 1998-1999.

41. Xie, J., Shi, H., Du, Z., Wang, T., Liu, X., Chen, S. 2016. Comparative genomic and functional analysis reveal conservation of plant growth promoting traits in Paenibacillus polymyxa and its closely related species. Scientific Reports, 1-12.

42. Yu, N. Y., Wagner, J. R., Laird, M. R., Melli, G., Rey, S., Lo, R., ... Brinkman, F. S. L. 2010. PSORTb 3.0: improved protein subcellular localization prediction with refined localization subcategories and predictive capabilities for all prokaryotes. Bioinformatics, 26(13), 1608-1615.

43. Zhang, Z., Yuen, G. Y. 1999. The role of chitinase production by Stenotrophomonas maltophilia strain C3 in biological control of Bipolaris sorokiniana. Phytopathology, 90(4), 384-389. 